\title{
The antigens of lung cancer
}

\author{
R L Souhami
}

The growth of interest in the biology of lung cancer is a welcome product of frustration with the results of current treatment. The last 15 years have seen a considerable increase in our knowledge of the disease, and we can but hope that therapeutic advances will result. It is the most common cause of death from cancer in men, and in the United States in the last two years it has overtaken breast cancer as the most common cause of fatal cancer in women. An additional spur to biological investigation has been the recognition of four pathological types of the disease. There is growing acceptance of the hypothesis that lung cancer starts in a cell capable of differentiating into various pathological forms (fig 1). This is supported by the occurrence of mixed pathological types (for example, mixed squamous and small cell). In cell lines and in biopsy material it has been shown that neuroendocrine features, typical of small cell lung cancer, can be found in adenocarcinoma and that cytokeratins, which are uniformly found in squamous cell carcinomas, are expressed in small cell lung cancer.

Small cell lung cancer shows the typical pathological features of neuroendocrine differentiation: neurosecretory dense core granules, chromogranin A, cytoplasmic L dopa decarboxylase, the glycolytic enzyme neurone specific enolase, and production of hormones and neuropeptides. There is some evidence that when some of these features are detected in any adenocarcinoma this is more likely to respond to chemotherapy, ${ }^{1}$ though more recent studies have indicated that the effect is small. ${ }^{2}$

These considerations indicate that the antigens detected in lung cancer are likely to be expressed, in some degree, in all pathological types and will be representative of antigens found in neuroendocrine, ${ }^{3}$ squamous, and glandular tissues, and in carcinomas at other sites. Some of these antigens are potential targets for antibody directed treatment (see

Reprint requests to: Professor Souhami below). They are molecules that are associated with a wide range of functions of normal fetal and malignant cells. Strictly speaking, they are not "tumour antigens" (though they are sometimes referred to as such) because they are not tumour specific in the sense of appearing on tumour cells only. Monoclonal antibodies, produced by somatic cell hybridisation, have led to the definition of a wide range of cellular antigens, many of them proteins whose function has now been well characterised and whose amino acid sequences have been determined. They are broadly categorised as cell-cell attachment molecules, antigens binding to extracellular matrix proteins, antigens that are receptors for transmembrane signal induction, and blood group antigens.

\section{Types of cellular antigens}

\section{CELL-CELL ATTACHMENT MOLECULES}

Carcinoembryonic antigens are a family of proteins closely related to the immunoglobulin gene "superfamily."4 Carcinoembryonic antigens are expressed during fetal life and reexpressed in various neoplasms, typically in adenocarcinomas. Other members of this "superfamily" include the neural cell adhesion molecule, and recent workshops on lung cancer antigens (see below) have shown that this is expressed in most small cell lung cancer lines and biopsy specimens, and appears to be an important marker of the neuroendocrine phenotype. Carcinoembryonic antigens are also expressed in small cell lung cancer and other forms of lung cancer and may be associated with an adverse prognosis. ${ }^{25}$ The neural cell adhesion molecule is a cell-cell attachment protein that is heavily glycosylated. It exists in several major isoforms. There are two transmembrane linked forms, a truncated form attached to membrane phospholipid (via glycosylphosphatidylinositol) and a soluble form in muscle and brain. The genetic basis for this variation lies in alternative splicing of the gene for the neural cell adhesion molecule. ${ }^{6}$ The molecule has the property of homophilic binding (fig 2). The degree of binding is inversely related to the amount of glycosylation. A heavily glycosylated form has been described in Wilms' tumour. The forms of the neural cell adhesion molecule expressed in small cell lung cancer have not yet been systematically analysed. Many monoclonal antibodies have been made to the neural cell adhesion molecule 
Figure 2 Major isoforms of neural cell adhesion molecule showing homophilic binding. The dark regions indicate repetitive domains. $\mathrm{Pl}-$ phosphotidylinositol linked form. A form of neural cell adhesion molecule is also synthesised that is detached from the cytoplasmic membrane.

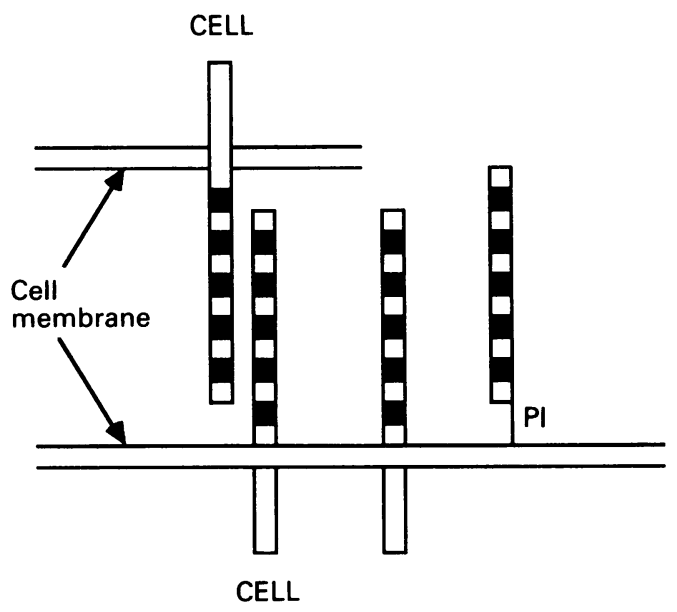

Figure 3 Binding of integrins to extracellular matrix proteins.

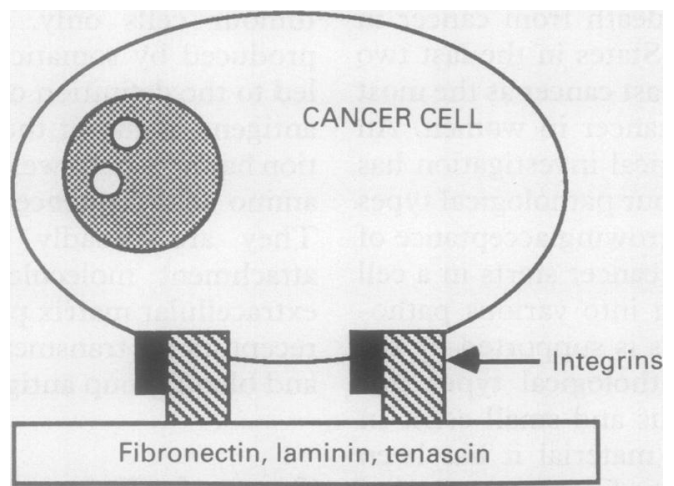

Fibronectin, laminin, tenascin

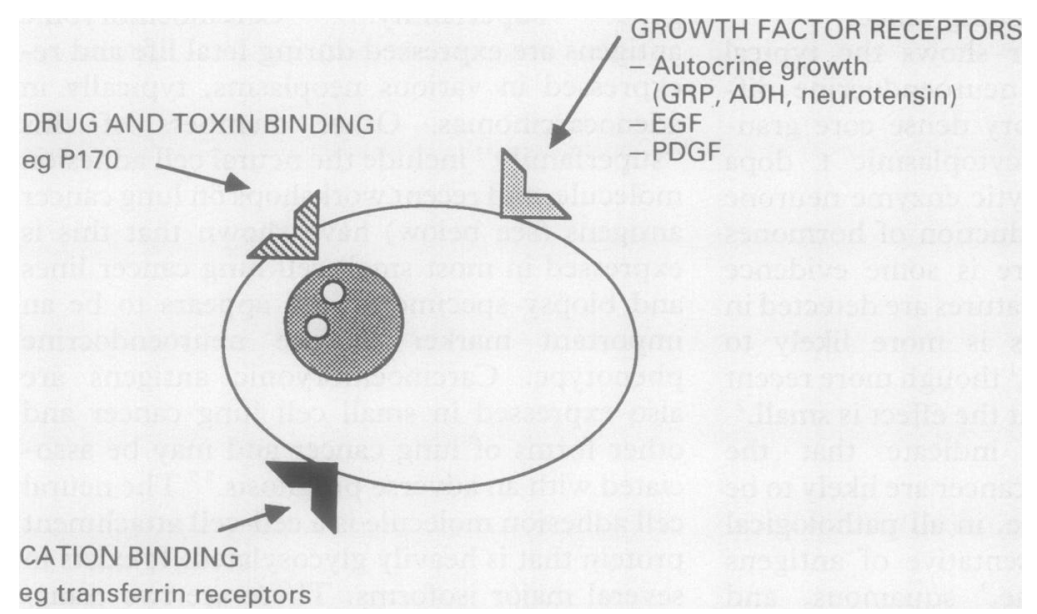

Figure 4 Some membrane receptor molecules, recognised by monoclonal antibodies, on the lung cancer cell. GRP - gastrin releasing peptide; $A D H$-antidiuretic hormone; $E G F$-epidermal growth factor; PDGF-platelet derived growth factor. and many appear to recognise a relatively restricted region of the peptide backbone.

Other carcinoembryonic antigen like molecules are myelin associated glycoprotein and an antigen found on melanoma cells. ${ }^{7} \mathrm{~A}$ surface glycoprotein of molecular weight $40 \mathrm{Kd}$ was found in the lung cancer workshops (see below) to be expressed on lung cancers and a wide range of epithelia and epithelial malignancies. The gene has been cloned ${ }^{8}$ and appears to be closely related to an extracellular matrix protein, nidogen. Other cell attachment molecules, such as the intercellular adhesion molecule, are expressed on melanoma and other cancer cells. The class I histocompatibility antigens are found on all forms of lung cancer, but class II is poorly expressed on small cell lung cancers, though its presence can be induced by treatment with interferon $\alpha$.

\section{ANTIGENS THAT BIND TO EXTRACELLULAR MATRIX} PROTEINS

Many tumour cells both secrete and have receptors for extracellular matrix proteins (fig 3). Proteins such as collagen, fibronectin, lamina, and tenascin are essential components of the extracellular matrix. Integrins are heterodimeric transmembrane receptor proteins that bind to laminin, collagen, and fibronectin. In doing so they link the cytoskeleton of the cell with the matrix. ${ }^{9}$ The integrin family is a complex in which the $\alpha$ chain varies and the $\beta$ peptide defines the class. The variety of integrin expression is apparently reduced in cancer. Integrins appear in a later stage of cellular differentiation and are found on squamous cancers. Glycolipid antigens $\left(\mathrm{GD}_{2}\right.$ and $\mathrm{GD}_{3}$ ) are also expressed in lung cancer and may be important in cell invasion in this and other tumours. ${ }^{10}$

\section{ANTIGENS THAT ARE RECEPTORS CONCERNED} WITH TRANSMEMBRANE SIGNAL INDUCTION The cell membrane contains a range of receptors for growth factors, cytokines, and toxins as well as proteins concerned with drug attachment and efflux. Figure 4 shows some of these proteins and indicates some of the diversity of function. The epidermal growth factor receptor is expressed on non-small cell lung cancers ${ }^{11}$ and receptors for insulin like growth factors on small cell lung cancers. These receptors and others, such as those for platelet derived growth factor, are widely distributed on tumours and normal cells. Of particular interest in small cell lung cancer is the expression of receptors for growth inducing peptides, such as gastrin releasing peptide (bombesin), which are secreted by the tumour and which, on becoming bound to the tumour cell, promote cell division-that is, autocrine growth stimulation.

Other membrane associated proteins concern cellular functions of detoxification and cation transport. The p170 glycoprotein is associated with cellular resistance to the effects of naturally occurring antitumour substances, such as doxorubicin, epipodophyllotoxin, and colchicine. The protein acts as a drug efflux mechanism and methods to circumvent its action may yet give useful therapeutic results. MBr1 is a glycosphingolipid expressed on breast and lung cancer cells whose function is not clear.

\section{BLOOD GROUP ANTIGENS}

Carbohydrate antigens on glycolipids are strongly expressed on many epithelial 
tumours. ${ }^{11}$ Many of these are blood group antigens such as Lewis ${ }^{x}$ and Lewisy, and some are expressed less (or not at all) on the normal epithelium from which the tumour is derived. In this sense they sometimes represent oncofetal antigens, which may be expressed

Lung cancer antigen classification based on the analysis of the Second Lung Cancer Antigen Workshop*

\begin{tabular}{|c|c|c|}
\hline Cluster & Monoclonal antibodies & Comments \\
\hline 1 & $\begin{array}{l}\text { RNL1, MOC-1, MOC-191, } \\
\text { NCC-LU-243, NCC-LU- } \\
\text { 246, SEN 6, SEN 36, NE 150, } \\
\text { S-L 11·14, NE } 25 \text { (also } \\
\text { UJ13A, ERIC-1 from other } \\
\text { sources) }\end{array}$ & $\begin{array}{l}\text { Neural cell adhesion molecule. }{ }^{10} \text { Evidence } \\
\text { for different epitopes. Form of molecule } \\
\text { on SCLC not known. Distribution: } \\
\text { SCLC, carcinoid, renal carcinoma, } \\
\text { neuroblastoma, nerve, muscle, thyroid } \\
\text { epithelium }\end{array}$ \\
\hline 2 & $\begin{array}{l}\text { MOC-31, MOC-38, MOC-151, } \\
\text { MOC-181, AUA 1, S-L 2.21, } \\
\text { probably PE-35 and S-L 4.20 }\end{array}$ & $\begin{array}{l}40 \mathrm{kDa} \text { transmembrane glycoprotein gene } \\
\text { is cloned.12 Efficient in immunotoxin } \\
\text { mediated cytotoxicity. Distribution: } \\
\text { SCLC, carcinoid, normal and } \\
\text { malignant epithelium }\end{array}$ \\
\hline w4 & $\begin{array}{l}\text { SWA 21, SWA 22, probably } \\
\text { SWA } 11\end{array}$ & $\begin{array}{l}\text { Glycosylated protein } 45 \mathrm{kDa} \text {. } \\
\text { Distribution: SCLC, neuroblastoma, } \\
\text { carcinoid, adenocarcinoma and } \\
\text { squamous carcinoma, renal tubules, } \\
\text { granulocytes }\end{array}$ \\
\hline 5 & SWA 4, SWA 23, LAM 8 & $\begin{array}{l}\text { Antigens of } 90-135 \text { and } 200 \mathrm{kDa} \text {, } \\
\text { probably sialoglycoproteins. } \\
\text { Distribution: SCLC, carcinoid, } \\
\text { adenocarcinomas, weakly with } \\
\text { squamous carcinomas, nerve, renal } \\
\text { tubules }\end{array}$ \\
\hline $5 A$ & $\begin{array}{l}\text { SWA 20, probably SEN } 3 \text { and } \\
\text { SEN } 31\end{array}$ & $\begin{array}{l}\text { Antigens of } 40,100,180 \mathrm{kDa} \\
\text { sialoglycoproteins. Distribution: similar } \\
\text { to cluster } 5\end{array}$ \\
\hline w6 & $\begin{array}{l}\text { MOV 15, NCC-ST-433, } \\
\text { probably NCC-LU-152 }\end{array}$ & $\begin{array}{l}\text { Le' hapten. Distribution: broad epithelial } \\
\text { reactivity }\end{array}$ \\
\hline w7 & NCC-ST-439, NCC-CO-450 & $\begin{array}{l}\text { High molecular weight mucins. } \\
\text { Distribution: broad epithelial reactivity }\end{array}$ \\
\hline w8 & $\begin{array}{l}\text { A-80, NCC-LU-35, NCC-LU- } \\
\quad 81\end{array}$ & $\begin{array}{l}\text { Blood group A trisaccharide. } \\
\text { Distribution: broad epithelial reactivity }\end{array}$ \\
\hline
\end{tabular}

^Fifty one of 87 monoclonal antibodies were not assigned to a cluster, so this is in no sense a complete description of the antigens to which monoclonal antibodies have been made.

SCLC-small cell lung cancer.

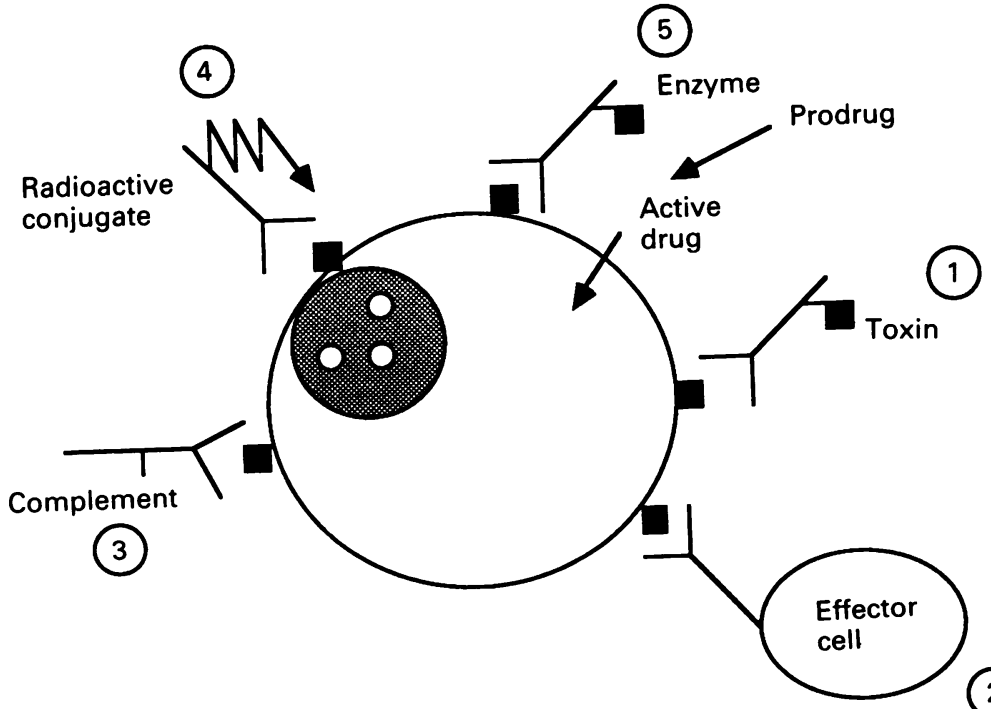

Figure 5 Potential mechanisms for tumour cell killing by monoclonal reagents. 1: a toxin is coupled to antibody that is internalised, resulting in toxin mediated cell death; 2: the antibody acts as a bridge to a cytolytic effector cell; 3: the antibody induces complement mediated lysis; 4: the antibody is conjugated to a radionuclide that irradiates the tumour; $5:$ the antibody is conjugated to an enzyme that activates an inert prodrug in the region of the tumour (or normal tissue). transiently during tissue development and are re-expressed in neoplasia.

Some of these carbohydrate antigens are also found on glycoproteins, such as mucins or adhesion molecules, and the patterns of glycosylation in these high molecular weight structures may be different in normal and malignant cells. Blood group and glycolipid antigens are expressed on both small cell and non-small cell lung cancers. ${ }^{12}$

Membrane receptors taking part in the transport of calcium, iron, copper, and other cations are found on the surface of lung cancer cells (and other tumour cells) as on normal cells and other tumours. Up regulation or altered expression of these receptors has not yet been described in lung cancer.

\section{Lung cancer antigen workshops}

Two recent workshops ${ }^{1314}$ have been undertaken to attempt to introduce a taxonomic description of the antigens being recognised by the numerous monoclonal antibodies to lung cancer cells. A summary of the major clusters of reactivity is given in the table. Cluster 1 is the neural cell adhesion molecul $\mathrm{e}^{15}$ and there are now numerous examples of monoclonal antibodies that react with this molecule. Many of them cross block, indicating recognition of a common epitope, but some do not. They appear to recognise protein rather than sugar residues. Cluster 2 is the gp40 glycoprotein previously described. Clusters W6 and W8 are blood group haptens, and W7 is a high molecule weight mucin. Clusters 4 and 5 are extremely interesting glycoproteins with both neural and epithelial reactivity, found on small cell lung cancer cells and of unknown function. The workshops showed that neuroendocrine differentiation was a much more pronounced feature of small cell lung cancer than of nonsmall cell lung cancer, but that overlap of neuroendocrine and epithelial features occurred.

\section{Clinical approaches using cell surface antigens}

Clinical interest in these antigens comes from their potential use as targets for antibody directed treatment (fig 5). Such treatment might be with radiolabelled antibody, where the cell and its neighbours might be killed by radiation, or by toxins (such as the ricin $\mathrm{A}$ chain) linked to antibody (gp40 may be especially effective at internalising bound antibody), or by more complex methods, such as the use of a prodrug administered with an antibody coupled to an enzyme, which converts the prodrug to a cytotoxic form only at the site at which the antibody-enzyme conjugate is bound (that is, the tumour). Other approaches use antibodies that lyse cells in the presence of complement or allow cell killing by effector cells such as activated cytotoxic T cells. Phase I and II clinical trials using these approaches are now beginning.

Some of the antigens are more promising targets than others. Ideally, the antigen should be expressed on most cells in all cases of a given 
type of tumour. In practice some degree of heterogeneity is always found. The antigen should be expressed on as small a number of normal tissues as possible, and especially not on those that are likely to be dose limiting (bone marrow precursor cells, for example). So far there has been little evidence that antigens unique to particular tumours (and not found in normal tissues) are likely to be found, but this may not invalidate the approach. Of course, the finding on tumour cells of altered epitopes of an antigen found on normal tissues would be a step towards increased specificity, but so far there is little indication that this is likely. New methods of production of monoclonal antibodies by techniques of molecular biology may make the rather "hit or miss" approach based on hybridomas obsolete. Progress in this approach to lung cancer treatment is highly probable.

1 Graziano SL, Mazio R, Newman N, et al. The use of neuroendocrine immunoperoxidase markers to predict chemotherapy response in patients with non small cell lung cancer. J Clin Oncol 1989;7:1389-406.

2 Ruckdeschel JC, Linniola RI, Mulshine JL, et al. The impact of neuroendocrine and epithelial differentiation on response and survival in lung cancer [abstract]. Proc Am Soc Clin Oncol 1991;A849.

3 Linniola RI, Mulshine JL, Steinber SM, et al. Neuroendocrine differentiation in endocrine and non-endocrine lung carcinomas. Am J Clin Pathol 1988;90:641-52.

4 Oikawa S, Imaj S, Moguchi T, et al. The carcinoembryonic antigen (CEA) contains multiple immunoglobulin-like antigen (CEA) contains multiple immunoglobulin-like
domains. Biochem Biophys Res Commun 1987;144:634-42.
5 Linniola RI, Ruckdeschel JC, Piantadosi S, et al. The impact of neuroendocrine and epithelial differentiation on recurrence and survival in patients with resected non small cell lung cancer: the LCSG experience [abstract]. Proc Am Soc Clin Oncol 1991;A850.

6 Owens GS, Edelman GM, Cunningham BA. Organisation of the neural cell adhesion molecule (N-CAM) gene: alternative exon usage as the basis for different membrane associated domains. Proc Natl Acad Sci USA 1987;84: 294-8

7 Salzer JL, Holmes WP, Colman DR. The amino acid sequences of the myelin-associated glycoproteins: homology to the immunoglobulin gene superfamily. $J$ Cell Biol 1987;104:957-65.

8 Simon B, Podolsky DK, Moldenhauer G, et al. Epithelial glycoprotein is a member of a family of epithelial cell surface antigens homologous to nidogen, a matrix adhesion protein. Proc Natl Acad Sci USA 1990;87: 2755-9.

9 Buck CA, Horwitz AF. Cell surface receptors for extracellular matrix molecules. Annu Rev Cell Biol 1987;13: cellular mat

10 Elder DE, Rodeck U, Thurin J, et al. Antigenic profile of tumour progression stages in human melanocytic nevi and melanomas. Cancer Res 1989;49:5091-6.

11 Weiner DB, Nordbert J, Robinson R, et al. Expression of the neu gene-encoded protein $\left(\mathrm{P}_{185^{\mathrm{neu}}}\right)$ in human non small cell lung carcinomas of the lung. Cancer Res 1990;50: 421-5.

12 Andrews CM, Seiler NS, Magnani JL. Detailed epitope mapping of carbohydrate antigens recognised by antibodies from the Lung Cancer Workshop. Br J Cancer 1991;63(suppl X14):36.

13 Souhami RL, Beverley PCL, Bobrow LG. Antigens of small cell lung cancer. First International Workshop. Lancet 1987;ii:325-6.

14 Souhami RL, Beverley PCL, Bobrow LG, Ledermann JA. Results of central data analysis: 2nd International Workshop on Small Cell Lung Cancer Antigens. J Natl Cancer Inst 1991;83:609-12.

15 Patel K, Moore SE, Dickson G, et al. Neural cell adhesion molecule (N-CAM) is the antigen recognised by monoclonal antibodies of similar specificity in small cell lung carcinoma and neuroblastoma. Int J Cancer 1989;44: 573-6. 